\title{
"Murs que parlen" y la Tarraco romana: experiencias y reflexiones sobre una incómoda relación
}

\author{
Darío Cobacho Velasco | Artista y gestor cultural \\ URL de la contribución <www.iaph.es/revistaph/index.php/revistaph/article/view/4919>
}

\section{Contexto del patrimonio mural de Tarragona}

En la experiencia vivida desde que iniciamos las diferentes intervenciones de arte urbano en la Asociación Polígon Cultural, en la ciudad de Tarragona, han sucedido muchas cosas: se ha venido desarrollando una comunidad amplia de personas interesadas en el grafiti y el arte urbano, se ha ganado terreno en el desarrollo de estas prácticas y las instituciones se han abierto más a comprender el fenómeno. Próximamente va a publicarse una humilde publicación retrospectiva (Cobacho, Grané y Blasco en prensa) que despejará dudas en muchos sentidos sobre la escena del grafiti y el arte urbano local. Gracias a esto he tenido la oportunidad de investigar su pasado muralista y he decidido elaborar estas líneas.

Pese a que poco a poco se han conquistado las calles y se ha hecho mucha pedagogía respecto a la pintura mural, cabe decir que el desarrollo del movimiento muralista en la ciudad de Tarragona representa un caso particular con respecto a otras capitales de provincia españolas ya que todo su urbanismo ha estado supeditado a la circunstancia de convivir con el conjunto arqueológico monumental más importante del país. En un contexto así, naturalmente el foco presupuestario y la prioridad política ha sido la preservación de los yacimientos de la Colonia Iulia Urbs Triumphalis Tarraco y, en consecuencia a dicha prioridad, los encargos artísticos y la tipología de proyectos realizados en la ciudad han seguido de forma hegemónica cánones tradicionales con olvido y ausencia casi absoluta de los movimientos de vanguardia y de renovación estética.

En diferentes publicaciones y artículos se ha dado ya a conocer el gran mosaico patrimonial de murales, inscripciones y manifestaciones plásticas que tiene lugar en Tarragona, que engloban épocas tan diferentes como el
Imperio Romano, la Edad Media, el Imperio Español, o de nuestro pasado más reciente de los siglos XX y XXI. Para muestra podemos enumerar: los frescos e inscripciones encontradas en la muralla romana y el anfiteatro (s. II a. de C.-s. IV d. de C.), los grafitos de caballeros del claustro de la Catedral de Tarragona (s. XV d. de C.), los esgrafiados barrocos de la Plaça del Fórum (s. XVII d. de C.), los frescos neoclásicos de la Casa Castellarnau (final del s. XVIII d. de C.), los grafitos de marchas militares de la Catedral (s. XIX d. de C.), las diferentes muestras de esgrafiados modernistas y novecentistas de la Casa Pilar Fonts (1911) o la Casa Ximenis (1914), los murales de la posguerra española como el de Antón Català Gomis en el Salón de Actos de la antigua Central Nacional-Sindicalista de Tarragona (1948) ${ }^{1}$, los murales de la vanguardia española como Grupo Aránzazu (Néstor Basterretxea y Rafael Ruiz Balerdi), Grupo Z (José Vento y Manolo Gil) y otros contemporáneos como José Cuní, Francisco Moreno Galván, Venancio Blanco y Joaquín Rubio Camín, todos ellos realizados en la antigua Universidad Laboral Francisco Franco (1956).

Por otra parte podemos destacar, entre otras muestras interesantes, el heterogéneo conjunto de murales cerámicos de gran formato repartidos en diferentes edificios de la Rambla Nova y la Rambla Lluis Companys, compuesto por obras de Julio Bono, Santiago Padrós, Joan Rebull, Josep M. ${ }^{a}$ Subirachs, Lluis M. ${ }^{\text {a }}$ Saumells, Josep

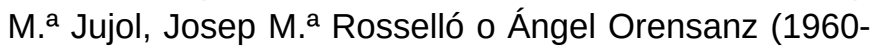
1970). Recomendamos visitar la cuenta de la Biblioteca Hemeroteca Municipal de Tarragona (L'Arxiu) que desde 2013 se encarga de buscar y documentar la información de todas estas obras en la sección Històries Enllaçades.

Como resulta evidente, tenemos una importante problemática en cuanto a la conservación y difusión de un 
a debate Dilemas del arte urbano como patrimonio

| coordinan Elena García Gayo y Laura Luque Rodrigo

acervo cultural de tal magnitud. Si analizamos la web de turismo nos damos cuenta de que las únicas tres rutas que ofrece la ciudad son el patrimonio romano, el medieval y el modernista. Cabe además, el tratamiento dado a las obras de vanguardia de la Laboral -de inestimable valor- que siguen a día de hoy, como relata Jordi Guerrero, "vergonzosamente arrinconadas de cualquier manera" (Guerrero Fernández 2017).

\section{Convivencia y competición por la imagen de la ciudad}

Con estos precedentes era de esperar que propuestas renovadoras como las que implica el movimiento del grafiti y el arte urbano iban a ser censuradas, perseguidas y, en el mejor de los casos, ignoradas. La prueba de esta relación incómoda la tenemos en el anuncio reciente de la ejecución de un mural sufragado por el ayuntamiento que funcionará como recreación plástica y didáctica de la extensión que tuvieron las gradas del anfiteatro romano. Lo curioso del caso que nos ocupa es que la obra se realizará en un lugar que simboliza a la perfección esta batalla contra la imagen contemporánea: el mural del anfiteatro (el segundo mural de temática romana y estética hiperrealista en la ciudad) será pintado en el muro que acogió en 2011 las obras de los escritores barceloneses Aryz y Sawe en el marco del Foro Ciutats Creactives de Arquitecturas Colectivas. Aquellas obras fueron pagadas también con dinero público y borradas a petición municipal el año siguiente de su ejecución. La razón expuesta para el borrado de los murales fue diversa en los medios de comunicación, pero asumimos que la cercanía al casco histórico tuvo mucho más que ver que la implantación del "futuro proyecto de museo de la Semana Santa".

Elena de Ortueta nos recuerda en su publicación De l'erudit al turista que precisamente esta tendencia de glorificar la ruina romana ha sido una forma de dar continuidad a la fórmula romántica "Tarraco quanta fuit, ipsa ruina docet” (Qué grande fue Tarraco, dicen sus ruinas). Una concepción desde mi punto de vista equivocada que concibe el patrimonio como algo congelado, inobjetable, intocable y, por tanto, estéril.

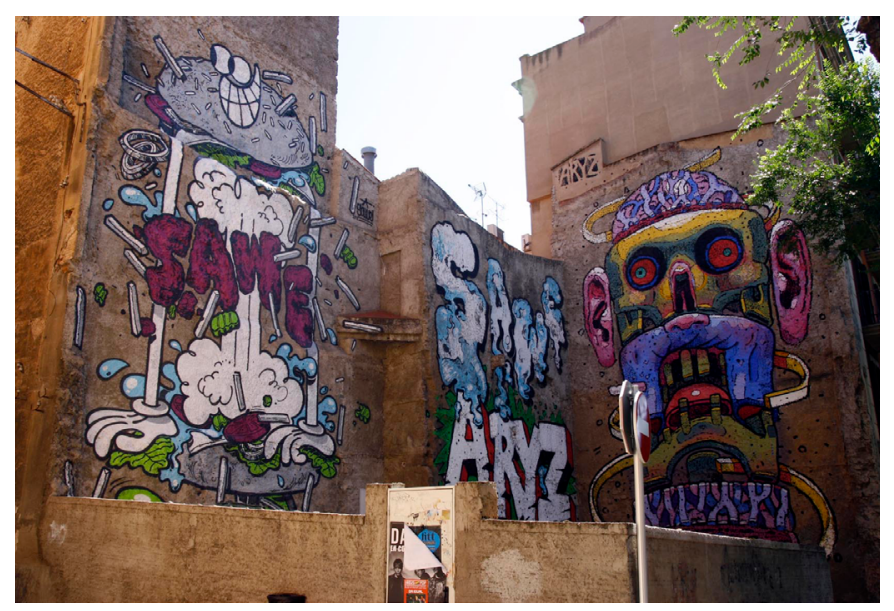

Mural de Aryz y Sawe en Tarragona, 2011 (borrado en 2012) | foto Aitor García

Más allá de esta tensión entre la renovación estética que supone el arte urbano y la preservación de una identidad muy concreta como ciudad patrimonio de la humanidad, hemos observado recientemente experiencias que nos hacen tener esperanza en la reconciliación de la imagen de la ciudad antigua y su revisión contemporánea. Estas relecturas no sólo son del todo practicables, sino que son un imperativo si queremos que las personas se interesen por nuestro patrimonio y lo hagan suyo. La exposición fotográfica Convivència de Montserrat Caballero (Caballero 2019), museóloga de los Servicios Territoriales de Cultura de la Generalitat de Catalunya en Tarragona, indagó el pasado año 2019 en el diálogo entre las estampas del patrimonio romano que se conservan y las estéticas industriales de la ciudad actual. Para la muestra se contó con una formidable selección de fotógrafos y fotógrafas, pues hay que recordar que Tarragona también es cuna del SCAN, un festival de referencia internacional en el mundo de la fotografía que se realiza desde el 2008.

Otra experiencia destacable ha sido el macromural realizado el 2018 por el artista local Mëgan en el Instituto Pons d'lcart. La obra enmarcada en el programa L'educació per la pau que organiza anualmente dicho centro educativo gira en torno a los acontecimientos de la Guerra del Francès o Guerra de la Independencia Española (1808-1814) e ilustra el asedio a la ciudad en 
el año 1811. Cabe señalar, como el mismo autor constató en diversos medios, que el mural sufrió un retraso de tres años en su realización debido entre otros motivos a la limitación en la gama de colores que impuso el municipio. Colores terrosos que se hicieron coincidir con la pintura de las fachadas del centro de la ciudad.

Finalmente, otra propuesta destacable fue Desc-obrim el teatre! (MNAT-EADT 2011), una colaboración entre la Escuela de Artes y Diseño de Tarragona (EADT) y el Museu Nacional Arqueològic de Tarragona realizada el 2011, en un proyecto que aunaba el muralismo, el arte urbano y el patrimonio para resolver de forma creativa la integración plástica de las vallas que rodean el Teatro Romano. Además de suponer un ejercicio práctico para los alumnos y alumnas del Ciclo de Artes Aplicadas al Muro, en el que aprendieron y experimentaron todas las fases de elaboración de una propuesta vinculada al patrimonio, supuso una puesta en valor de muchos de los fondos del museo que seguramente habían pasado desapercibidos o que no se habían puesto en su contexto espacial en las calles (como las máscaras del teatro). Claramente este tipo de acciones no malmeten la contemplación de las ruinas de Tarraco, sino que, todo lo contrario, profundizan y ayudan a contextualizar mejor aquellos lugares que sin una guía o un toque de color que llame la atención pasarían desapercibidos.

Como hemos visto, a pesar de haberse dado algunas experiencias en la ciudad, éstas no dejan de ser una rara excepción a la norma de reproducir el mito de Tarraco como una ciudad fúnebre de piedra y mármol gris.

Es decir: reproducir una ciudad cromofóbica -usando una expresión de Fernando Figueroa- en la que se reprime cualquier atisbo de color en la proximidad al casco antiguo. Una imagen -bajo mi punto de vista de absoluta decadencia- que ni siquiera es fiel a la imagen que debieron observar sus contemporáneos en las calles romanas: llenas de grafitos y propaganda electoral, de espacios públicos llenos de vida, de esculturas y fachadas policromadas con relieves, mosaicos o pinturas al fresco.

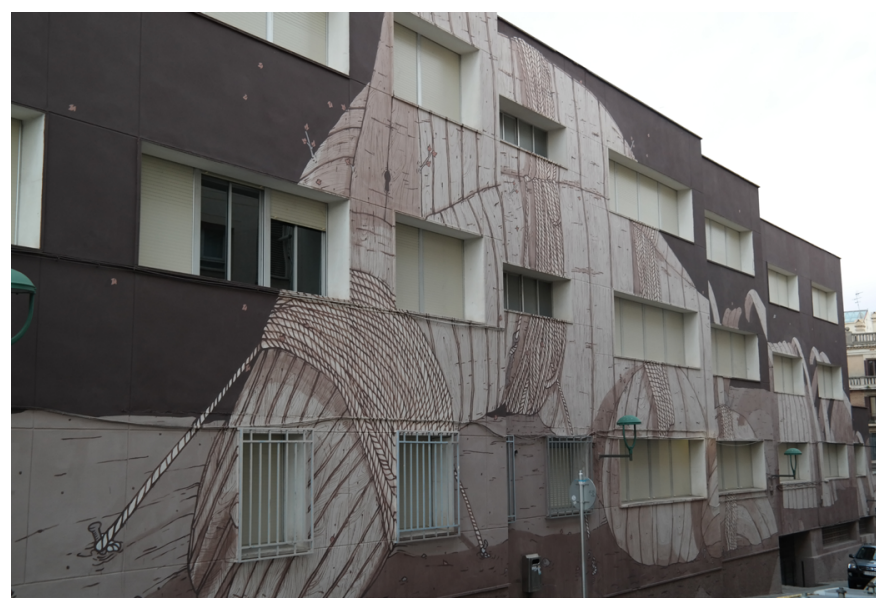

Mural de Mëgan sobre la Guerra del Francès (2019) | foto Darío Cobacho

\section{Arte urbano con potencial patrimonial}

Como cierre a estas reflexiones sobre las relaciones entre patrimonio y arte urbano o muralismo en Tarragona me gustaría insistir en la gran oportunidad que representa este movimiento para repensar nuestras ciudades: más allá de suponer una forma de ilustrar el patrimonio invisibilizado o la memoria oral, los archivos o las estampas fotográficas, las intervenciones artísticas ponen de relieve la actualidad que siguen teniendo para nosotras determinados acontecimientos, fenómenos o hitos del pasado. Es decir, los hacen presentes y los devuelven a las nuevas generaciones.

Un caso concreto que en diferentes ocasiones he traído respecto de experiencias exitosas en los barrios periféricos de Tarragona ha sido el de Las mujeres de Bonavista pintadas en el 2015 por la artista argentina Mariela Ajras. La obra parte de una fotografía de archivo de los años sesenta en la que aparece un grupo de mujeres de la mano, con delantal y las bolsas de la compra. La instantánea había sido robada por un fotógrafo de boda que al girarse inmortalizó a las vecinas. Una fotografía que de otra manera hubiera quedado en un cajón, ahora captaba la atención pública y se resignificaba en el nuevo contexto de auge de un movimiento feminista muy potente. Fue un sincero homenaje a las luchadoras que lo mismo traían el pan a casa como lo mismo se disponían a organizar una huelga de autobuses. 
El mural no sólo fue una mejora urbanística -al final es lo de menos-, sino que supuso un cambio en la concepción de su propio pasado para los vecinos de este barrio, que sintieron con orgullo aquel hito al sentirse representados en una identidad propia de construcción comunal y obrera. Además de que por una vez, el municipio se hubiera acordado de que ellos existían al tenerles en cuenta para el proyecto (estando en la periferia más absoluta).

El pasado año 2019 nos sorprendió una noticia insólita: el dueño del edificio donde se había pintado el mural quería repintar de blanco toda la fachada porque los inquilinos detectaron humedades. Pero más insólita aún fue la respuesta que recibimos: los vecinos que participaron en la ejecución y disfrutado viendo los avances de la obra ya se habían organizado para salvarla del blanqueo. Nos reunimos y conseguimos el consejo de la restauradora Maite Serna, pudiendo pagar la compra y la aplicación de material hidrofugante transparente que preservaría el mural algunos años más, acabando a su vez con las humedades del inmueble. Las mujeres siguen a día de hoy dando que hablar a los vecinos, murmurando historias de esta barriada a todo aquel que pasa a verlas.

Al vivir la experiencia de gestión de este tipo de iniciativas, no me cabe la menor duda de su potencial como activadores de presencias y relatos urbanos. Cabe preguntarse quizás si estos relatos pasarán a formar parte del gran grueso de olvidos de nuestras sociedades (como lo fue el grafiti romántico) o si conseguirán preservar su huella a todas luces contra-hegemónica y revitalizadora de las calles.

\section{NOTAS}

1. Mural al fresco desaparecido debido a que en algún momento se decidió borrarlo. Era una alegoría sobre el trabajo y los oficios, cuya escena central estaba presidida por una figura entronizada con un báculo, que tanto podría tratarse de una alegoría de la institución católica como un retrato con ropas de soldado cruzado del propio Franco. Las fotografías en la web del autor no permiten saberlo. Disponible en: www.catalagomis.cat/ obra-mural/

\section{BIBLIOGRAFÍA}

- Ayuntamiento de Tarragona (2021) Històries Enllaçades. Disponible en: www.tarragona.cat/patrimoni/fons-documentals/ biblioteca-hemeroteca/compartim-histories 19/04/2021]

[Consulta:

- Cobacho, D., Grané, P. y Blasco, N. (en prensa) Murs que parlen: una mirada retrospectiva a l'art urbà de Tarragona. Tarragona: Conselleria de Joventut de l'Ajuntament de Tarragona

- Guerrero Fernández, J. (2017) La Universidad Laboral de Tarragona (1952-1956) como materia de un nuevo orden visual en la arquitectura. En: Actas del IV Congreso Nacional Pioneros de la Arquitectura Moderna Española La arquitectura como obra integral Madrid, 19-20 de Mayo de 2017. Fundación Alejandro de La Sota

- Caballero, M. (2019) Catàleg d'exposició. Convivència, Els Monu-ments de Tàrraco Patrimoni de La Humanitat al Segle $X X I$. Tarragona: Serveis Territorials de Cultura, Generalitat de Catalunya a Tarragona. Disponible en: www.issuu.com/ iamcultura/docs/full_sala_mdecat [Consulta: 19/04/2021]

- MNAT-EADT (2011) Desc-obrim el teatre! Una proposta creativa i de col laboració. El mirador i la intervenció sobre la tanca del teatre romà de Tarra-gona. Catálogo del proyecto y la exposición. Tarragona: Diputació de Tarragona 